\title{
Quarantining arriving travelers in the era of COVID-19: balancing the risk and benefits a learning experience from Bahrain
}

\author{
Abdulkarim Abdulrahman ${ }^{1,2}$, Manaf AlSabbagh ${ }^{3}$, Abdulla AlAwadhi ${ }^{1,4}$, Jaffar A. Al-Tawfiq ${ }^{5,6,7}$, Ali A. Rabaan 5 ,
} Stephen Atkin ${ }^{8}$ and Manaf AlQahtani ${ }^{1,8,9^{*}}$ (D)

\begin{abstract}
The quarantine period imposed to travelers in many countries due to COVID19 is a major obstacle for any traveler. Lifting the quarantine period could lead to significant improvement in people's quality of life and any country's economy. Bahrain have used two quarantine models from arriving passengers. We report data about the incidence of COVID19 on arriving passengers at Bahrain International airport. Infection rates were reported on arrival, during quarantine and after leaving quarantine. Results showed that travelers had low incidence of COVID19 on arriving and during the quarantine period, while becoming at higher risk after leaving quarantine. We concluded that quarantine requirement maybe lifted for arriving travelers. Testing upon arrival with implementation of the public health preventative measures can minimize the risk of transmission.
\end{abstract}

Keywords: Travelers, Quarantine, COVID19, SARS-CoV2, Public health

\section{Background}

The outbreak of severe acute respiratory syndrome coronavirus 2 (SARS-CoV-2) infections have infected more than 65 million people worldwide and Bahrain has witnessed over 87,000 cases to date [1]. This pandemic had its implications on all aspects of life, and it especially affected many countries economically. Different countries instated quarantine measures for international arrivals. A 14 day quarantine with testing upon exit has been a common practice [2].

The quarantine period is an obstacle for travelers. There is potential improvement in people's quality of life (QOL) and to the country's economy should this quarantine period be lifted. Quarantine hinders people from attending their work and business in timely manner. There are issues that require urgency such as, diplomatic

\footnotetext{
* Correspondence: drmanaf@gmail.com

${ }^{1}$ National Taskforce for Combating the Corona Virus, Riffa, Bahrain

${ }^{8}$ Royal College of Surgeons in Ireland-Bahrain, Muharraq, Bahrain

Full list of author information is available at the end of the article
}

missions and urgent business dealings, which could be delayed and canceled due quarantine. Implementing quarantine incur a significant cost to the health authorities, as there is a need to test, track and follow up. This can prove to be a financial and a resources burden. Quarantine also have a negative psychological effects. Stemming from people lack ability of managing quarantine challenges; Such as, social isolation, loss of freedom, and uncertainty over disease status [3].

Maldives, Turkey, UAE, Mexico and Brazil have removed the quarantine period for visitors. Other countries have stratified arrivals based on the risk of the country of origin. This has been a common measures in European countries like Austria, Slovakia, Switzerland and Netherlands.

The quarantine measures may not be necessary. In this manuscript we discuss Bahrain's data and experience about quarantining of international travelers. 
Table 1 Summary of the returning travelers in quarantine with percent of positive SARS-CoV-2 test

\begin{tabular}{llllll}
\hline Study Period & $\begin{array}{l}\text { Days of } \\
\text { Quarantine }\end{array}$ & $\begin{array}{l}\text { Number of } \\
\text { travelers }\end{array}$ & $\begin{array}{l}\text { SARS-CoV-2 positive } \\
\text { on arrivals }\end{array}$ & $\begin{array}{l}\text { SARS-CoV-2 positive during } \\
\text { the quarantine period }\end{array}$ & $\begin{array}{l}\text { SARS-CoV-2 positive due to } \\
\text { local transmission }\end{array}$ \\
\hline May 15-June 30, 2020 & 14 & 10,784 & $335(3.1 \%)$ & $63(0.6 \%)$ & $276(2.6 \%)$ \\
July 1-August 16, 2020 & 10 & 15,070 & $178(1.2 \%)$ & $28(0.2 \%)$ & $312(2.1 \%)$ \\
\hline
\end{tabular}

With the 14 days quarantine, $2.6 \%$ were infected after the quarantine period and $0.6 \%$ within the quarantine period. With the 10 -day quarantine, $2.1 \%$ were infected after the quarantine period and $0.2 \%$ within the quarantine period. There was no difference in these two quarantine strategies employed for the travelers

\section{Main text}

The quarantine measures were especially important early during the pandemic, when the majority of cases in Bahrain were travelers. Between 24 February and 31 March, travelers made up $60 \%$ of all cases in Bahrain, with the local cases being contacts of those travelers. As local transmission within the country grew, local cases became the majority of cases. In April and May, local transmission cases made up more than $95 \%$ of all cases in Bahrain. This was due to increased local transmission and decreased in traveling. There were 8477 cases due to local transmission in May compared to 2349 cases in April.

We retrospectively examined the data of all arrivals at Bahrain International Airport between 15th May to 30th June 2020. There were 10,784 passengers arriving and all were tested. 335 (3.1\%) tested positive upon arrival. All other travelers entered quarantine for 14 days after testing negative. Only 63 passengers $(0.6 \%)$ who entered quarantine tested positive. Furthermore, 276 (2.6\%) of the arrivals who were negative after completion of the quarantine period, got infected by coming in contact to a positive case in Bahrain.

Several studies report that most infected individuals are no longer contagious 10 days after symptoms development $[4,5]$. The incubation period for SARS-CoV-2 was thought to have a median time of 4-5 days from exposure to symptoms onset [6]. $97.5 \%$ of infected people who develop symptoms would do so within 11.5 days of SARS-CoV-2 infection [6]. Moreover, it was observed that the time from exposure to onset of infectiousness was shorter than the incubation period estimated [6]. A Chinese study suggested that infectiousness starts 2.3 days prior to symptom onset [7]. Hence, the Bahraini authorities concluded that a PCR test through a NP sample at day 10 would be sufficient to detect at least $97.5 \%$ of all infected individuals. Moreover, the authorities also issued new guidelines for international passengers where quarantine rules were imposed for 10 days upon arrival after their first RT-PCR test.

Based on this policy, another analysis of the data was conducted. Between 1st July \& 16th August, all 15,070 arrivals at Bahrain International Airport were tested. 178 (1.2\%) tested positive upon arrival. $28(0.2 \%)$ passengers tested positive during the 10 days quarantine period. 312
(2.1\%) tested positive while in Bahrain due to local transmission.

Conversely, under these two models of quarantine protocols, only few cases turned positive during quarantine (Table 1). The percentage of arrivals diagnosed with SARS-CoV-2 infection after leaving quarantine did not increase and remained low. Thus, quarantine rules were withdrawn, and the testing was continued for all passengers upon arrival.

With community transmission rising in the country, travel restriction and compulsory quarantine alone cannot control the outbreak. Preventive measures such as self-isolating if symptomatic, social distancing, wearing a face mask, washing hands and proper hygiene maintenance is more crucial than quarantining travelers. These measures, in addition to testing on arrival, can be sufficient to prevent the transmission of an infected case traveling into the country and can improve the country's economy and the QOL of the arrivals. This is especially important as reopening measures have been planned and starting.

\section{Conclusion}

The results from our study showed that only a minority of travelers were infected with SARS-CoV-2. This highlights that quarantine for travelers may not be necessary. However, testing upon arrival with implementation of the public health preventative measures can minimize the risk of viral transmission.

\section{Abbreviations \\ SARS-CoV-2: Severe acute respiratory syndrome coronavirus 2; COVID- 19: Corona Virus Disease of 2019; RT-PCR: Real time polymerase chain reaction; NP: Nasopharyngeal; QOL: Quality of life}

\section{Acknowledgments}

We would like to acknowledge the efforts of Team Bahrain in their amazing work during the period of this pandemic. The collaborative effort from all have helped to keep the country safe.

\section{Authors' contributions}

MAS gathered the data. MQ, AK analyzed the data and concluded the inferences and scripted first draft of the manuscript. MQ AK and JAA participated in the design of the study. SA and AAR reviewed the manuscript and helped to draft the manuscript. AIA assisted in revising and scripting the manuscript. All authors read and approve the manuscript. 


\section{Availability of data and materials}

The datasets used and/or analyzed during the current study are available from the corresponding author on reasonable request.

Ethics approval and consent to participate

Approved by National COVID19 research committee.

\section{Consent for publication}

Not Applicable.

\section{Competing interests}

The authors declare that they have no competing interests.

\section{Author details}

'National Taskforce for Combating the Corona Virus, Riffa, Bahrain. ${ }^{2}$ Mohammed bin Khalifa Cardiac Centre, Riffa, Bahrain. ${ }^{3}$ Planning and Economic Studies Directorate, Ministry of Finance and National Economy, Manama, Bahrain. ${ }^{4}$ Department of Medicine, Bahrain Defense Force Hospital, Riffa, Bahrain. ${ }^{5}$ Infectious Disease Unit, Specialty Internal Medicine, Johns Hopkins Aramco Healthcare, Dhahran, Saudi Arabia. ${ }^{6}$ Department of Medicine, Indiana University School of Medicine, Indianapolis, IN, USA. ${ }^{7}$ Department of Medicine, Johns Hopkins University School of Medicine, Baltimore, MD, USA. ${ }^{8}$ Royal College of Surgeons in Ireland-Bahrain, Muharraq, Bahrain. ${ }^{9}$ Internal Medicine, Infectious Diseases and Clinical Microbiology, Bahrain Defense Force Hospital, Riffa, Bahrain

Received: 24 September 2020 Accepted: 14 December 2020 Published online: 12 January 2021

\section{References}

1. Coronavirus COVID-19 - Ministry of Health. Available from: https://www. moh.gov.bh/?lang=en. Cited 2020 Sept 13

2. More than 80 countries have imposed travel bans to curb the new coronavirus. The Economist; 2020. Available from: https://www.economist. com/graphic-detail/2020/03/16/more-than-80-countries-have-imposedtravel-bans-to-curb-the-new-coronavirus. Cited 2020 Nov 16.

3. Brooks SK, Webster RK, Smith LE, Woodland L, Wessely S, Greenberg N, et al. The psychological impact of quarantine and how to reduce it: rapid review of the evidence. Lancet. 2020;395(10227):912-20.

4. CDC. Coronavirus Disease 2019 (COVID-19). Centers for Disease Control and Prevention; 2020. Available from: https://www.cdc.gov/coronavirus/2019ncov/hcp/disposition-in-home-patients.html. Cited 2020 Sep 13.

5. Bullard J, Dust K, Funk D, Strong JE, Alexander D, Garnett L, et al. Predicting infectious SARS-CoV-2 from diagnostic samples. Clin Infect Dis Off Publ Infect Dis Soc Am. 2020;71(10):2663-2666.

6. Lauer SA, Grantz KH, Bi Q, Jones FK, Zheng Q, Meredith HR, et al. The incubation period of coronavirus disease 2019 (COVID-19) from publicly reported confirmed cases: estimation and application. Ann Intern Med. 2020;172(9):577-82.

7. He X, Lau EHY, Wu P, Deng X, Wang J, Hao X, et al. Temporal dynamics in viral shedding and transmissibility of COVID-19. Nat Med. 2020;26(5):672-5.

\section{Publisher's Note}

Springer Nature remains neutral with regard to jurisdictional claims in published maps and institutional affiliations. 